\title{
How to make yourselves redundant
}

\author{
Fiona Godlee editor in chief
}

The BMJ

Books and blogs about management and leadership are full of exhortations to make yourself redundant: find aspects of your job that don't need doing or that someone else could do; constantly innovate for smarter ways of working to release your time and energy; make it your aim to do yourself out of a job.

How does this advice translate to medicine? Two UK government announcements this week suggest some ideas. The first, from England's health secretary, Matt Hancock, called for a greater focus on prevention (doi:10.1136/bmj.k4684). If properly funded and implemented over time, this should indeed help more people to keep away from doctors. But it will happen only if we resist the urge to medicalise prevention. Instead of people (doctors and patients) spending time and money on health checks that lack an evidence base and marginally effective pills for primary prevention, we should be looking for ways for doctors to step away from people's lives. The most effective preventive interventions reside largely outside medicine-in better social security, education, housing, transport, and the environment, as our editorialists make clear (doi:10.1136/bmj. $\mathrm{k} 4673$ ). "If we value health above all, then increased spending on the NHS, at the expense of other services, will not be enough," they say.
This doesn't mean doctors have no role. Good doctors have always looked beyond the care of individual patients, seeking to understand the root causes of the illnesses and injuries they treat, and they have then used whatever means they have at their disposal to advocate for political and societal change.

The second of this week's government announcements was about investment in five new centres to develop artificial intelligence for faster diagnosis (doi:10.1136/bmj.k4686). What scope here for making doctors obsolete? In a Head to Head debate this week (doi:10.1136/bmj.k4563), and in a linked podcast, Jörg Goldhahn suggests that it is almost limitless, even to the point that machines can be more trustworthy and less judgmental than humans. He makes a good case, but Vanessa Rampton and Giatgen Spinas are not convinced. Nor, more importantly, are our patient commentators (doi:10.1136/bmj. k4669). Between them, Michael Mittelman, Sarah Markham, and Mark Taylor have 61 years of patient history in health systems worldwide. "None of us can envisage our relationships with our many human doctors changing because of artificial intelligence," they say. They see AI as becoming a useful and innovative aide, "as the servant rather than the director of our medical care."

It looks like your redundancy is some way off. 